\title{
ETNOMATEMATIKA MASYARAKAT PENGRAJIN ANYAMAN RAJAPOLAH KABUPATEN TASIKMALAYA
}

\author{
Oleh: \\ Mega Nur Prabawati \\ Program Studi Pendidikan Matematika, Universitas Siliwangi \\ megarafaadzani@gmail.com
}

\begin{abstract}
ABSTRAK
Sebagian masyarakat sering tidak menyadari telah menerapkan ilmu matematika dalam kehidupannya. Kecenderungannya adalah mereka memandang bahwa matematika hanyalah suatu mata pelajaran yang hanya dipelajari dan diperoleh dibangku sekolah. Padahal tidak hanya itu, matematika sering digunakan dalam berbagai aspek kehidupan, misalnya dalam mengukur, mengurutkan suatu bilangan, dan masih banyak lagi yang lainnya. Keberadaan etnomatematika kerajinan anyaman ini dapat digunakan sebagai sumber belajar dan tentu saja dapat membuat siswa ataupun masyarakat lebih memahami bagaimana budaya mereka berhubungan dengan matematika.
\end{abstract}

Kata Kunci : Etnomatematika, Kerajinan Anyaman.

\begin{abstract}
Some people often do not realize has been applying mathematics in their life. The tendency is they looked at that math is simply a subjects who only studied and obtained in College. But not only that, the math is often used in various aspects of life, such as in measure, sort of a number, and much more. The existence of the etnomatematika woven crafts can be used as a source of learning and of course can make students or the community better understand how their culture related to mathematics.
\end{abstract}

Keywords: Ethnomathematics, Woven Crafts

\section{PENDAHULUAN}

Matematika dianggap sebagai sesuatu yang netral dan terbebas dari budaya (culturraly-free). Seperti yang diungkapkan oleh Rosa dan Orey (2011) bahwa "mathematics always taught in scholl as a culturaly free subject that involved learning supposedly universally accepted facts, concept and content". Matematika dipelajari di sekolah sebagai mata pelajaran yang tidak terkait dengan budaya yang secara umum pembelajarannya maliputi fakta-fakta, konsep, dan materi. Matematika juga dianggap sebagai ilmu pengetahuan yang sempurna dengan kebenaran yang objektif dan dirasakan jauh dari realitas kehidupan sehari-hari.

Menurut D'Ambrosio (Gerdes, 1996:912) pada masa sebelum dan diluar sekolah hamper semua anak di dunia telah menjadi "matherate" artinya, mereka mampu mengembangkan kemampuan untuk menggunakan bilangan, menghitung, dan menggunakan beberapa pola inferensi. Tetapi, seorang individu yang dengan sempurna telah mampu mengunakan bilangan, operasi, bentuk geometris, dan gagasan, ketika disekolah dihadapkan pada pendekatan yang sama sekali baru dan formal melalui fakta $\neg$-fakta. Sebagai akibatnya, terbentuklah penyumbatan psikologis yang tumbuh sebagai penghalang antara perbedaan model-model numerik yang dipelajari di sekolah dengan pemikiran geometris yang sudah dipelajarinya dari kehidupan nyata sebelum atau diluar sekolah, sehingga tahap awal 
pendidikan matematika memberikan pengaruh pada anak rasa kegagalan, ketergantungan, bahkan kehilangan kemampuan matematisyang telah dimiliki pada masa pra sekolah. Hal tersebut menunjukkan bahwa pembelajaran matematika disekolah terlepas dari kehidupan nyata yang kaya akan budaya nyata dan peradaban.

Namun penelitian-penelitian yang telah dilakukan menunjukkan bahwa terdapat keterkaitan antara matematika dan budaya. Menurut Clements (Karnilah, 2013:2) salah satunya dapat dilihat dari hasil pertemuan-pertemuan International Community of Mathematics Education yang menyatakan bahwa permasalahan yang terkait dengan budaya mau tidak mau akan mengelilingi proses belajar mengajar matematika, bahkan mengelilingi pula semua bentukbentuk matematika.

Turmudi (2012:5) menyatakan bahwa matematika berurusan dengan gagasan, matematika bukan tanda-tanda sebagai akibat dari coretan pensil, bahkan kumpulan benda-benda fisik berupa segitiga, namun berupa gagasan yang direpresentasikan oleh benda-benda fisik. Sehingga menurut Turmudi terdapat tiga sifat utama dari matematika. Pertama, matematika sebagai objek yang ditemukan dan dicptakan manusia. Kedua, matematika itu dicptakan bukan jatuh dengan sendirinya, namun muncul dari dari aktivitas yang objeknya telah tersedia, serta dari keperluan sainsdan kehidupan keseharian. Ketiga, sekali diciptakan objek matematika memiliki sifat-sifat yang ditentukan secara baik.

Pembelajaran matematika sekolah saat ini banyak mengadopsi dari pembelajaran matematika Negara luar yang dianggap lebih maju. Seperti yang ditulis dalam artikel yang berjudul Budaya Pengaruhi Ilmu Matematika pada harian umum pikiran rakyat 14 Januari 2010, pengadopsian kurikulum ini tidaklah salah hanya saja pendekatan budaya setempat dalam pembelajaran mateatika perlu diterapkan juga agar penguasaan siswa lebih sempurna. Menurut hemat peneliti, Indonesia dengan keragaman budayanya sudah seharusnya memasukkan nilai-nilai budaya setempat ke dalam pembelajaran matematika, agar matematika tidak dianggap sebagai ilmu pengetahuan yang jauh dari realitas kehidupan. Hal ini dikarenakan dalam aktivitas budaya terdapat ide-ide matematis yang dianggap sebagai hal yang penting dalam pembelajaran matematika.

\section{PEMBAHASAN}

\section{A. Etnomatematika}

Pada abad 19-an sudah dikenal beragam istilah dengan kata awal ethno yang mengalami perluasan makna, Powell (Francois, 2010:1518) ethno diatikan sebagai sebagai suatu konsep yang mengacu pada kelomok etnis, kelompok nasional, kelompok ras, kelompok professional, kelompok dengan dasar filosofis atau ideologis, kelompok social dan budaya. Beragam kajian mengenai ethno telah dikenal seperti ethnomusicology, ethnobotany, ethnopsychology. Jika ethnoscinece dimaknai sebagai kajian scientific berkaitan dengan fenomena-fenomena teknologi yang berkaitan langsung dengan latar belakang social, ekonomi, dan budaya. Ethnolanguage dimaknai kajian bahasa dalam hubungannya dengan keseluruhan budaya dan kehidupan social, sehingga dengan analogi yang sama ethnomathematicsdimaknai sebagai kajian matematika (ide matematika) dalam hubungannya dengan keseluruhan budaya dan kehidupan social (Gerdes, 1996:916); (Gerdes, 1997:343). 
Di akhir tahun 1970-an dan di awal tahun 1980, pertumbuhan kesadaran akan aspek social dan budaya dari matematika dan pendidikan matematika mulai muncul dikalangan matematikawan. Dukungan - dukungan terhadap hal tersebut dapat ditemui dalam berbagai pertemuan-pertemuan internasional para matematikawan, pendidik matematika, dan pembuat kebijakan politik pendidikan dimana keobjektifan social terhadap pendidikan matematika secara tulus dipertimbangkan.

Salah seorang yang berperan penting dalam melakukan inisiatif-inisiatif tersebut yakni Ubiratan D' Ambrosio seorang matematikawan Brazil dan guru matematika. Pada periode itu D'Ambrosio meluncurkan Ethnomathematical program sebagai metodologi untuk melacak dan menganalisis proses produksi, pemindahan, penyebaran, dan pelembagaan pengetahuan (matematika) dalam berbagai macam system budaya, yang kemudia D'Ambrosio dikenal sebagai Intellectual Father of The Ethnomathematical Program. D'Ambrosio membedakan matematika akademik yang biasa diajarkan dan dipelajari disekolah dengan etnomatematika yang digambarkan sebagai matematika yang dipraktekkan diantara kelompok budaya yang dapat diindentifikasi seperti masyarakat, suku, kelompok buruh, anak-anak dari kelompok tertentu dan kelas professional. Menurut beliau, mekanisme sekolah menggantikan praktekpraktek tersebut dengan praktek-praktek lain yang setara yang telah memperoleh status matematika, yang telah diambil alih dari bentuk aslinya dan kembali disusun menurut versi suatu sistem. Kemudian munculah pertanyaan "Haruskah kita memasrahkan kurikulum sekolah dan menggantinya dengan etnomatematika? jelaslah tidak". D'Ambrosio menyatakan bahwa kurikulum matematika sekolah semestinya memasukan etnomatematika sedemikian hingga memfasilitasi siswa untuk mendapat pengetahuan, umtuk memahami, dan menyelaraskan pengetahuannya dengan praktek-praktek (budaya) yang telah dikenal (Gerdes, 1996:912-913).

Dari segi etimologis, D'Ambrosio (Peard, 1996:42) awalnya mendefinisikan ethnomathematics sebagai praktik matematika yang dilakukan oleh kelompok-kelompok budaya tertentu, seperti masyarakat suku tertentu, kelompok buruh, anak-anak dari kelompok usia tertentu, kelas professional dan sebagainya. Identitas dari kelompok tersebut biasanya bergantung pada focus minat atau kepentingan, motivasi dan kode-kode tertentu dan jargon yang tidak terkait dengan bidang matematika akademik.

\section{B. Anyaman Tradisional dan Konsep Berpikir Masyarakat Rajapolah}

Menurut Hoenigman (Wikipedia, 2008) Anyaman Merupakan wujud kebudayaan, yang termasuk dalam artefak. Artefak adalah wujud kebudayaan fisik yang berupa hasil dari aktivitas, perbuatan, dan karya semua manusia dalam masyarakat berupa benda-benda atau hal-hal yang dapat diraba, dilihat, dan didokumentasikan. Anyaman pertama kali digunakan manusia, yaitu untuk membantu dalam kehidupannya sehari-hari.

Anyaman merupakan salah satu bentuk lain dari gerabah yang terbuat dari pengaturan bilahbilah selain dari gerabah yang terbuat dari tanah liat. Banyak sekali jenis anyaman tradisional yang terdapat di suku Sunda. Dimana beda material beda juga nama dan teknik menganyam. Di Rajapolah sendiri setidaknya ada 3 jenis material yang digunakan yaitu adalah bambu, pandan, dan mendong. Tiap bahan memiliki karakteristik dan beberapa diantaranya memiliki filosofi yang sangat kuat. 
Motif anyaman tradisional sangat beragam hal ini dikarenakan bahan yang digunakan dalam pembuatan anyaman berbeda-beda, namun beberapa motif anyaman meskipun bahan berbeda ada yang diberi nama sama, hal ini melihat dari kesamaan bentuk motifnya. Dilihat dari keadaan diatas, masyarakat Sunda Rajapolah telah memiliki sebuah pemikiran yang sangat logis dan jauh dari sifat mistis dalam pembuatan motif anyaman, sehingga nama yang diberikan merupakan nama anyaman yang diambil dari alam dan kehidupan yang mereka jalani.Beberapa bahan anyaman memiliki filosofi yang kuat. Bambu adalah salah satu bahan anyaman yang sangat kental dengan makna, apalagi jika kita menghubungkan dengan suku Sunda. Masyarakat Sunda sudah sedemikian lama berhubungan akrab dengan bambu, banyak pengalaman leluhur yang bisa dipetik, sejak lahir hingga mati, orang Sunda selalu dipertemukan dengan bambu.

Menurut Pengurus Harian Yayasan Bambu Indonesia, Jatnika (Kompas, 2007), menuturkan "Di masa lalu, seluruh rangkaian hidup orang Sunda penuh dengan bambu," katanya. pada saat dilahirkan, bayi-bayi Sunda dahulu dilepaskan dari ari-arinya menggunakan sembilu dari bambu. Lalu bayi tersebut disimpan dalam ayakan atau saringan besar terbuat dari bambu. Ketika bayi lelaki disunat, pisau penyunatnya terbuat dari bambu. Saat belajar berjalan, orangtuanya membuat tonggak-tonggak dari bamboo di halaman yang bisa dikitari oleh anak tersebut. Saat makin besar, ia dibuatkan Jajangkungan (mainan dari bambu) untuk berlatih keseimbangan, kakinya akan naik ke bambu yang tinggi dan ia berjalan di atasnya sehingga bisa melihat desa dari atas. Makin besar, mereka mengasah keterampilan tangan dan kekompakan dengan teman melalui berbagai permainan, seperti bebedilan atau pistol mainan, mereka juga membuat alat musik untuk hiburan, seperti angklung, calung, dan suling.

Di kalangan keluarga, mereka menggunakan daun bambu untuk membungkus makanan seperti bacang dan wajit. Mereka juga memakan rebung atau anak bambu untuk sayur. Seharihari mereka tinggal di rumah bambu dan membuat mebel dari bambu. Perkakas rumah tangga seperti pengki (tempat sampah) hingga aseupan (pengukus) terbuat dari anyaman bambu. Ketika sudah tua, orang Sunda membuat tongkat dari bambu. Saat meninggal, ia ditandu dengan keranda bambu dengan penutup jenazah dari anyaman bambu.

Bambu juga merupakan bahan bangunan yang hingga kini digunakan oleh masyarakat Sunda yaitu digunakan dalam pembuatan sekat atau dinding rumah yang tidak lain sering disebut bilik, tentu saja digunakan di rumah-rumah yang terdapat di Perkampungan dengan menggunakan 4 hingga 6 buah penyangga dari batu, dan menurut penelitian rumah jenis ini dapat meminimalisir guncangan gempa. Selain itu pula bambu digunakan sebagai alat musik, angklung dan suling sudah digunakan orang Sunda sejak abad ke-7. Selain bambu bahan dasar lain seperti pandan memiliki nilai filosofi dalam kehidupan masyarakat Sunda. Pandan memiliki karakteristik yang mudah dibentuk, halus, dan lentur. Pandan mempunyai nilai filosofi yang cukup tinggi, menurut Ali Sastramidjaja (2007) nilai filosofi yang terkandung dari pandan dapat kita lihat pada produk anyaman, yaitu adalah tikar pandan atau samak.

Pada jaman dahulu masyarakat Sunda mempunyai kebiasaan bahwa samak merupakan keluarga. hal ini dapat dilihat dari keseharian masyarakat Sunda dahulu, mereka lahir diatas tikar, saat ada waktu berkumpul mereka ada diatas tikar dan ketika meninggal ditutup oleh tikar pula. Selain itu pandan juga memiliki keunggulan yang mungkin tidak semua suku atau bangsa tahu, yaitu saat bayi suku Sunda lahir, darah yang tercecer pada tikar pandan, dapat dibersihkan dengan mudah dan bau dari darah dapat hilang dengan cepat, selain digunakan 
dalam proses kelahiran, samak digunakan pada saat seseorang meninggal, dimana jasadnya akan ditutup oleh kain kafan dan ditutup oleh tikar pandan, menurut warga sekitar dengan tikar itu sendiri maka bau mayat tidak akan tercium, sehingga tidak akan menimbulkan fitnah atau kejadian yang tidak diinginkan.

Selain dari bahan pembuat anyaman, filosofi kehidupan masyarakat Sunda dapat dikaji dari segi bentuk benda anyaman yang mewakili filosofi hidup suku Sunda. Menurut Mamat Sasmita (Pendiri Rumah Baca Buku Sunda) pada boboko (tempat nasi) bentuknya yang unik, bentuk atasnya yang membulat dan bawahnya yang menggunakan alas berbentuk persegi merupakan filosofi hidup masyarakat Sunda yaitu "tekad kudu buleud, hidup kudu masagi" yang artinya menurut bahasa tekad harus bulat, dan hidup harus persegi, yang secara garis besar bisa diartikan kita harus mempunyai tekad yang teguh dan tidak goyah dan hidup kita harus teratur.

\section{Ide Matematis}

Etnomatematika muncul sebagai konsep baru yang merupakan pengaruh timbal balik antara matematika, pendidikan, budaya, dan politik. Etnomatematika dinyatakan sebagai sebuah kajian terhadap ide-ide matematik pada masyarakat primitive. Ide-ide matematik terdapat pada setiap budaya, akan tetapi yang diutamakan adalah bagaimana mereka mengungkapkannya dan konteks-konteks khusus yang terdapat pada suatu budaya akan berbeda dengan budaya yang lain. Perbedaannya bukan terletak pada kemampuan untuk berpikir abstrak secara logis, tetapi terletak pada pemikiran subjek, anggapan dasar budaya, dan situasi apa yang muncul saat proses berpikir.

Istilah ide matematis muncul dalam buku yang ditulis Maria Ascher. Dalam buku ini menganalisis mengenai beberapa contoh dari ide-ide matematis, seperti sistem bilangan, sistem kekerabatan, sistem navigasi, karakteristik desain, dan analisis permainan. Menurut Ascher dan Ascher (1997:25), ide-ide matematis meliputi segala sesuatu yang berkaitan dengan bilangan, logika, konfigurasi spasial, dan kombinasi atau susunan dalam sistem dan struktur. Ascher mengakui bahwa terdapat dua aspek dalam etnomatematika, yaitu memahami hubungan antara ide-ide matematis dan budaya serta bagaimana memodifikasi pendidikan matematika dengan memasukan ide-ide tersebut.

Penelitian etnomatematika dalam ranah pendidikan dapat digunakan untuk mengungkap ideide yang terdapat dalam aktivitas budaya tertentu atau kelompok sosial tertentu untuk mengembangkan kurikulum matematika untuk, dengan dan oleh kelompok tersebut. Sehingga matematika dapat memiliki bentuk yang berbeda-beda dan berkembang sesuai dengan perkembangan masyarakat pemakainya. Sejalan yang diuangkapkan oleh Gerdes (1996:930) yaitu "use of ideas embedded in the activities of certain cultural or social (marginalized) group within a society to develop a mathematical curriculum for and with/ bt this group".

\section{Pemanfaatan Etnomatematika Kerajinan Anyaman Rajapolah dalam Pembelajaran Kajian Geometri}

"A tessellation is a special type of pattern that consists of geometric figures that fit without gaps or overlaps to cover the plane" (O'Daffer, [4]:676). Kutipan di atasmenyatakan bahwa teselasi merupakan suatu pola khusus yang terdiri dari bangun-bangungeometri yang disusun tanpa pemisah/jarak untuk menutupi suatu bidang datar.Istilah lain yang sering digunakan 
untuk menyebut teselasi adalah pengubinan."Teselasi atau pengubinan merupakan konsep antar cabang ilmu pengetahuan,yaitu matematika dan seni”" (Rokhmah, [5]:1). Ketika teselasi digunakan oleh beberapaseniman dan tukang batu, teselasi mengacu pada konsep artistik. Sedangkan dalampembelajaran matematika, teselasi meliputi beberapa konsep-konsep matematika yanglebih dalam seperti segi banyak beraturan, segi banyak tidak beraturan, kekongruenan,sudut dalam, jumlah sudut dalam suatu segi banyak, simetri, translasi, refleksi, danrotasi.

Prinsip teselasi tersebut banyak diterapkan dalam kehidupan sehari-hari, sepertipada teknik pemasangan ubin, pembuatan motif kain, desain pola wallpaper dan lainlain(Depdiknas [3]). Bahkan di alam pun bisa ditemukan contoh teselasi yang terjadi secara alami, yaitu pada sarang lebah. Bangun-bangun geometri yang bisa menteselasi contohnya persegi, segitiga, segi lima beraturan, segi enam beraturan dan bisa juga berupa kurva. Beberapa definisi terkait teselasi diberikan sebagai berikut:

\section{Regular Tesselation}

"Such a tesselation, made up of congruent regular polygons of one type, all meeting edge to edge and vertex to vertex is called a regular tesselation" (O’Daffer, [4]:677). Hanya ada tiga poligon beraturan yang dapat menteselasi bidang datar yaitusegitiga, persegi, dan segienam beraturan.

\section{Semiregular Tesselation}

"A tesselation formed by two or more regular polygons with the arrangement of polygons at each vertex the same is called a semiregular tesselation" (O'Daffer,[4]:677). Dua hal penting yang dimiliki oleh semi regular tesselation adalah teselasi inidibentuk oleh poligon-poligon beraturan dan setiap puncak pada pertemuan polygon-poligonini adalah sama.

\section{A Demi Regular Tesselation}

"A demi regular tesselation is a tessellations of regular polygons that has exactly two or three different polygon arrangements about its vertices" (O’Daffer, [4]:688).

Dari uraian di atas, dapat dikatakan bahwa beberapa kerajinan anyaman Rajapolah terkandung unsur matematika salah satunya adalah penggunaan prinsip teselasi atau pengubinan. Karena mengandung unsur matematika maka hasil-hasil kerajinan anyaman ini dapat dimanfaatkan dalam pembelajaran dikelas terutama sebagai sumber belajar atau menghasilkan suatu model atau metode pembelajaran berbasis etnomatematika kerajinan anyaman Rajapolah.

\section{KESIMPULAN DAN SARAN}

Etnomatematika pada kerajinan anyaman Rajapolah dapat dimanfaatkan sebagai sumber belajar dalam pembelajaran matematika, menambah wawasan siswa mengenai keberadaan matematika yang ada pada salah satu unsur budaya yang mereka miliki, meningkatkan motivasi dalam belajar serta memfasilitasi siswa dalam mengaitkan konsep-konsep yang dipelajari dengan situasi dunia nyata. 


\section{DAFTAR PUSTAKA}

Ascher\&Ascher. (1997). Ethnomathematics. Dalam A.B. Powell\& M. Frankenstein (Penyunting), Ethnomathematics Challenging Eurocentrism in Mathematics Education (hlm 25-50). Albany: State University of New York.

Gerdes, P. (1996). Ethnomathematics and Mathematics Education. Dalam International Handbook of Mathematical Education (hlm 909-943). Dordrecht: Kluwer Academic Publiser.

Karnilah, N. (2013). Study Ethnomathematics: Penanggalan Sistem Bilangan Masyarakat Adat Baduy. (Skripsi). Universitas Pendidikan Indonesia. Bandung.

O’Daffer, Phares G. 2008. Mathematics for Elementary School Teachers. Fourth Edition. Pearson Education.

Peard, R. (1996). Ethnomathematics. Dalam Review of Mathematics in Australia 1992-1995 Bill Atweh, Ed. (hlm. 41-49). Washington, D.C : ERIC Clearinghouse.

Rosa, M. \& Orey D. (2009). Ethnomathematics: The Cultural Aspect of Mathematics. Revista Latinoamericana de Etnomatematca, 4(2) hlm32-54. 